\title{
Rivaroxaban versus aspirin in prevention of venous thromboembolism following total joint arthroplasty or hip fracture surgery: a meta-analysis
}

\author{
Bangsheng $\mathrm{Hu}^{1+}$, Lianxiang Jiang ${ }^{1+}$, Haixia Tang ${ }^{2}$, Meizhu $\mathrm{Hu}^{1}$, Jun $\mathrm{Yu}^{1}$ and Zeping Dai ${ }^{i^{*}}$ (D)
}

\begin{abstract}
Objective: To evaluates the efficacy and safety of rivaroxaban versus aspirin in prevention of venous thromboembolism (VTE) following total hip (THA) or knee arthroplasty (TKA) or hip fracture surgery.

Methods: Major databases were systematically searched for all relevant studies published in English up to October 2020. The meta-analysis was conducted using RevMan 5.3 software.

Results: In total, 7 studies were retrieved which contained 5133 patients. Among these patients, 2605 patients (50.8\%) received rivaroxaban, whereas 2528 patients (49.2\%) received aspirin. There were no statistical difference between aspirin and rivaroxaban for reducing VTE $\left(R R=0.75,95 \% \mathrm{Cl} 0.50-1.11, P^{2}=36 \%, p=0.15\right)$, major bleeding $\left(\mathrm{RR}=0.94,95 \% \mathrm{Cl} 0.45-2.37, \mathrm{P}^{2}=21 \%, p=0.95\right)$, and all-cause mortality $\left(\mathrm{RR}=0.88,95 \% \mathrm{Cl} 0.12-6.44, P^{2}=0 \%, p=\right.$ $0.90)$ between the two groups. Compared with aspirin, rivaroxaban significantly increased nonmajor bleeding (RR $=$ $1.29,95 \% \mathrm{Cl} 1.05-1.58, P^{2}=0 \%, p=0.02$ ).

Conclusion: There was no significant difference between aspirin and rivaroxaban in prevention of venous thromboembolism following total joint arthroplasty or hip fracture surgery. Aspirin may be an effective, safe, convenient, and cheap alternative for prevention of VTE. Further large randomized studies are required to confirm these findings.
\end{abstract}

Keywords: Rivaroxaban, Aspirin, Thromboembolism, Arthroplasty, Meta-analysis

\section{Introduction}

Venous thromboembolism (VTE) is a serious perioperative complication and one of the main causes of unintended death during perioperative period [1-4]. VTE, including deep vein thrombosi (DVT) and pulmonary embolism (PE), is one of the well-recognized complications after total joint arthroplasty. Virchow, a German

\footnotetext{
* Correspondence: zpdai@wnmc.edu.cn

${ }^{\dagger}$ Bangsheng $\mathrm{Hu}$ and Lianxiang Jiang contributed equally to this work. 'Department of Anesthesiology, The First Affiliated Hospital of Wannan Medical College, No.2, West Road of Zheshan, Wuhu 241000, Anhui, China Full list of author information is available at the end of the article
}

physiologist of the last century, believed that a clot is a change in the nature of the blood in a blood vessel under certain conditions [5]. In various pathological conditions, abnormal activation of the coagulation system in the blood can lead to the formation of emboli. Currently, there are three recognized factors of thrombosis, that is, the damage of vessel wall, abnormal blood flow, and abnormal coagulation system. Epidemiological studies have shown that more than half of hospitalized patients worldwide are at risk for venous thromboembolism [6]. Currently, the main clinical anticoagulants used include direct oral anticoagulants like rivaroxaban, 
a factor Xa inhibitor, and enoxaparin, a low molecular weight heparin (LMWH). However, it is a controversial topic since aspirin has emerged for a few years as a potential cost-effectiveness alternative for the prevention of thrombosis during arthroplasty.

Rivaroxaban is an oral highly selective factor Xa blocker that competitively inhibits both free and bound factor Xa and prothrombin activity, thus effectively and safely preventing deep vein thrombosis [7]. In recent years, it has been clinically used in many countries due to its good anticoagulant effect. Aspirin is a cheap, universal, and widely available antiplatelet drug. The efficacy of aspirin in prevention of cardiovascular and cerebrovascular ischemic diseases has been proved, but whether aspirin should be used as a routine drug for prevention of VTE after surgery is still controversial $[8,9]$.

Thus, studies of clinical trials conducted to compare the effects of rivaroxaban versus aspirin in preventing VTE. We conducted a meta-analysis to evaluate the efficacy and safety of rivaroxaban versus aspirin in prevention of VTE after total hip (THA) or total knee arthroplasty (TKA) or hip fracture surgery.

We present the following article in accordance with the PRISMA Reporting Checklist. And the PRISMA Reporting Checklist is provided in the Supplementary files.

\section{Materials and methods \\ Methodology}

We searched PubMed, Embase, the Cochrane Library, and EBSCO. Reviews, meetings, case reports, and related references in eligible studies were also included. Limits were set to literatures published in English up to October 2020. RevMan 5.3 software was used to carry out the meta-analysis. The search terms included "rivaroxaban", "aspirin", "venous thromboembolism", "bleeding", "perioperative period", "arthroplasty", "replacement", and "anticoagulants".

\section{Selection criteria}

The following standards were required for the included studies: (1) patients receiving rivaroxaban and aspirin after total joint arthroplasty or hip fracture surgery, (2) primary endpoint outcome was VTE and bleeding events, and (3) studies only published in English. The exclusion criteria consisted of the following: (1) excluding literature reviews, case reports, animal experiments, laboratory studies, and repeated publications and (2) excluding information to provide incomplete literature.

\section{Data extraction and management}

Study search, selection, abstraction, and quality assessment were all performed by two independent reviewers and all disparate opinions were resolved through discussion.

\section{Assessment of the quality of the studies}

The methodological quality of the included studies was estimated independently by two authors based on The Cochrane Risk of Bias criteria. Each quality item was graded as low risk, high risk, or no clear risk. The seven items used to assess bias in each trial included randomization sequence generation, allocation concealment, blinding of participants and personnel, blinding of outcome assessment, incomplete outcome data, selective reporting, and other biases.

\section{Outcomes}

The primary effectiveness outcome was adjudicated symptomatic venous thromboembolism, which was defined as DVT involving the popliteal vein or more proximal leg veins (including the femoral, common femoral, and iliac veins and inferior vena cava) or PE. The primary safety outcome was bleeding, including major or clinically relevant nonmajor bleeding. Secondary outcome measures were all-cause mortality.

\section{Statistical analysis}

RevMan 5.3 software was used to analyze the extracted data. Relative risk (RR) was used as effect size for counting data, and each effect size and its $95 \%$ confidence interval $(\mathrm{CI})$ were used to represent the results. The included studies were first tested for clinical heterogeneity. If there was no heterogeneity between the studies $\left(I^{2}<\right.$ $50 \%)$, the fixed effect model was selected for metaanalysis. On the contrary, there was heterogeneity among the studies $\left(I^{2}>50 \%\right)$; the reasons for the heterogeneity were analyzed, and factors of heterogeneity were analyzed using subgroups. If there was statistical heterogeneity between the two groups, but no clinical heterogeneity or statistical difference, the random effect model was used for analysis. Descriptive analysis was used when the heterogeneity of the two groups was too large or data sources could not be found. Funnel plot was used to indicate the publication bias.

\section{Results}

\section{Study selection process}

In this study, 1933 related literatures were initially retrieved. After reviewing the titles and abstracts, 1513 obviously unrelated literatures were excluded and 65 literatures were enrolled. Through full text reading, a total of 65 republished literatures and literatures with no research results were again excluded, and 7 studies $[4,10-15]$ were finally included, with a total of 5133 patients. Among the 7 studies, there were 2605 patients in the rivaroxaban group and 2528 patients in the aspirin group. PRISMA flowchart of the selection process is shown in Fig. 1. 


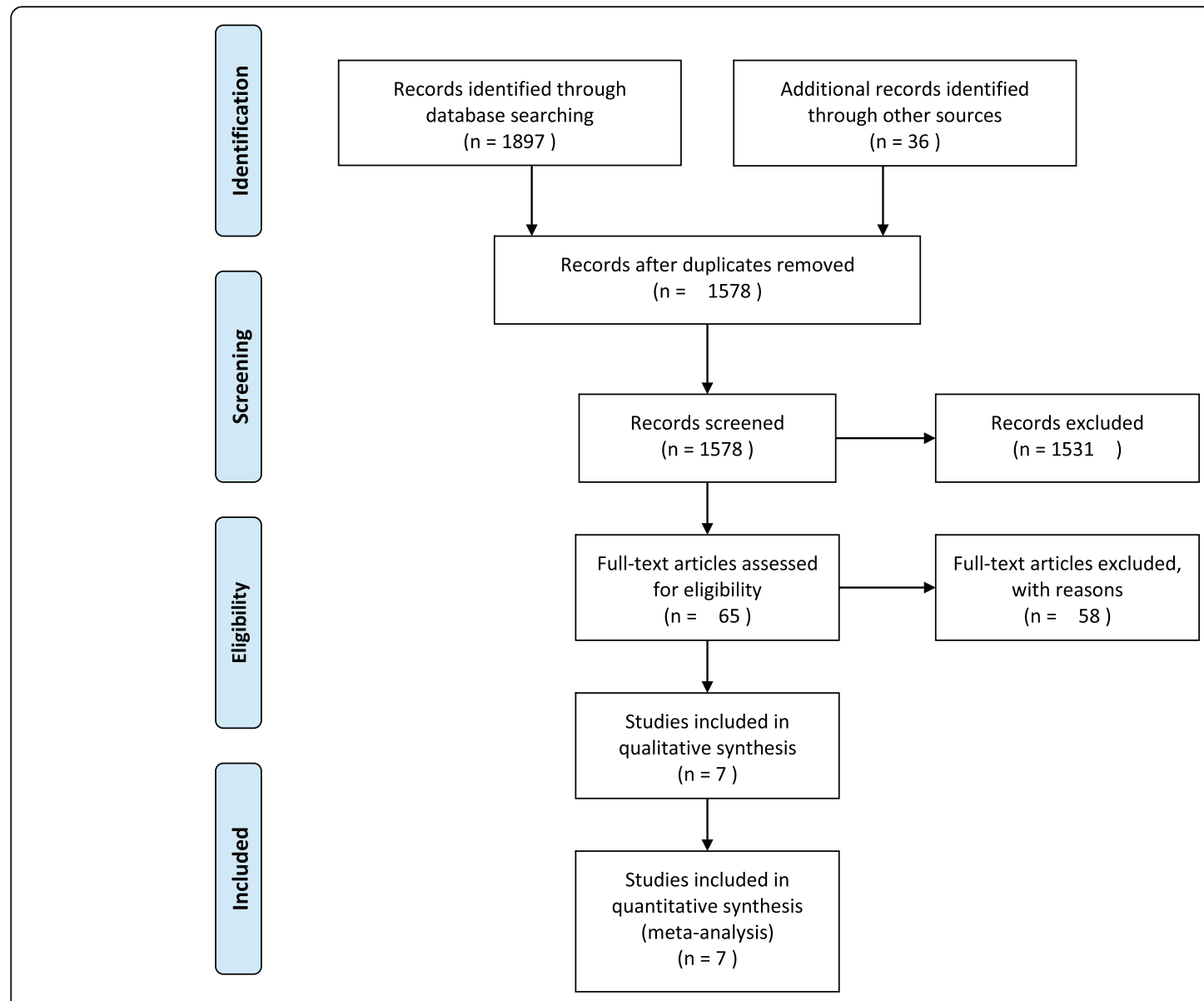

Fig. 1 PRISMA flowchart of the selection process

Table 1 Characteristics of studies included in the meta-analysis

\begin{tabular}{|c|c|c|c|c|c|c|c|c|}
\hline First author & Year & Country & $\begin{array}{l}\text { Sample number } \\
\text { (rivaroxaban/ } \\
\text { aspirin) }\end{array}$ & $\begin{array}{l}\text { Average age } \\
\text { (years) } \\
\text { (rivaroxaban/ } \\
\text { aspirin) }\end{array}$ & $\begin{array}{l}\text { Type } \\
\text { of } \\
\text { surgery }\end{array}$ & Intervention (rivaroxaban/aspirin) & $\begin{array}{l}\text { Follow- } \\
\text { up }\end{array}$ & Endpoints \\
\hline Jiang [10] & 2014 & China & $60 / 60$ & $63.8 \pm 6.7 / 65.1 \pm 7.5$ & TKA & $\begin{array}{l}10 \mathrm{mg} \text { once daily, } 14 \text { days/100 mg once } \\
\text { daily, } 14 \text { days }\end{array}$ & 42 days & VTE \\
\hline Zou [11] & 2014 & China & $102 / 110$ & $63.50 / 62.70$ & TKA & $\begin{array}{l}10 \mathrm{mg} \text { once daily, } 14 \text { days } / 100 \mathrm{mg} \text { once } \\
\text { daily, } 14 \text { days }\end{array}$ & 28 days & VTE, nonmajor bleeding \\
\hline Colleoni [12] & 2018 & Brazil & $18 / 14$ & $\begin{array}{l}67.11 \pm 7.65 / 71.21 \pm \\
6.35\end{array}$ & TKA & $\begin{array}{l}10 \mathrm{mg} \text { once daily, } 14 \text { days/300 mg once } \\
\text { daily, } 14 \text { days }\end{array}$ & 90 days & VTE, all-cause mortality \\
\hline Anderson (a) [4] & 2018 & Canada & $902 / 902$ & $\begin{array}{l}60.90 \pm 11.00 / 61.30 \\
\pm 11.10\end{array}$ & THA & $\begin{array}{l}10 \mathrm{mg} \text { once daily, } 30 \text { days } / 81 \mathrm{mg} \text { once } \\
\text { daily, } 30 \text { days }\end{array}$ & 90 days & $\begin{array}{l}\text { VTE, major bleeding, } \\
\text { nonmajor bleeding, all- } \\
\text { cause mortality }\end{array}$ \\
\hline $\begin{array}{l}\text { Anderson (b) } \\
{[4]}\end{array}$ & 2018 & Canada & $815 / 805$ & $\begin{array}{l}64.70 \pm 8.40 / 64.60 \pm \\
8.70\end{array}$ & TKA & $\begin{array}{l}10 \mathrm{mg} \text { once daily, } 9 \text { days } / 81 \mathrm{mg} \text { once } \\
\text { daily, } 9 \text { days }\end{array}$ & 90 days & $\begin{array}{l}\mathrm{VTE}, \text { major bleeding, } \\
\text { nonmajor bleeding, all- } \\
\text { cause mortality }\end{array}$ \\
\hline Lindquist [13] & 2018 & USA & $440 / 360$ & $65.4 / 65.8$ & $\begin{array}{l}\text { THA or } \\
\text { TKA }\end{array}$ & $\begin{array}{l}10 \mathrm{mg} \text { once daily, THA: } 35 \text { days, TKA: } 12 \\
\text { days/325 mg twice daily, THA: } 35 \text { days, } \\
\text { TKA: } 12 \text { days }\end{array}$ & 30 days & $\begin{array}{l}\text { major bleeding, nonmajor } \\
\text { bleeding }\end{array}$ \\
\hline $\begin{array}{l}\text { Yuenyongviwat } \\
{[14]}\end{array}$ & 2019 & Thailand & $76 / 79$ & $\begin{array}{l}71.41 \pm 6.17 / 70.08 \pm \\
5.22\end{array}$ & TKA & $\begin{array}{l}10 \mathrm{mg} \text { once daily, } 14 \text { days } / 100 \mathrm{mg} \text { once } \\
\text { daily, } 14 \text { days }\end{array}$ & 42 days & $\begin{array}{l}\text { VTE, major bleeding, } \\
\text { nonmajor bleeding }\end{array}$ \\
\hline Huang [15] & 2019 & China & 192/198 & $\begin{array}{l}67.8 \pm 16.9 / 69.4 \pm \\
17.4\end{array}$ & HFS & $\begin{array}{l}10 \mathrm{mg} \text { once daily, } 14 \text { days } / 100 \mathrm{mg} \text { once } \\
\text { daily, } 16 \text { days }\end{array}$ & 90 days & $\begin{array}{l}\text { VTE, major bleeding, } \\
\text { nonmajor bleeding }\end{array}$ \\
\hline
\end{tabular}

TKA Total knee arthroplasty, THA Total hip arthroplasty, HFS Hip fracture surgery, VTE Venous thromboembolism, Anderson (a) the type of surgery in this study was THA, Anderson (b) the type of surgery was TKA 
Table 2 Risk of bias assessment for included studies according to the Cochrane Collaboration's tool

\begin{tabular}{|c|c|c|c|c|c|c|}
\hline First author & $\begin{array}{l}\text { Random } \\
\text { allocation }\end{array}$ & $\begin{array}{l}\text { Hidden } \\
\text { distribution }\end{array}$ & $\begin{array}{l}\text { Blind } \\
\text { method }\end{array}$ & $\begin{array}{l}\text { Incomplete outcome } \\
\text { data }\end{array}$ & $\begin{array}{l}\text { Selective reporting of } \\
\text { results }\end{array}$ & $\begin{array}{l}\text { Other } \\
\text { bias }\end{array}$ \\
\hline Jiang [10] & Randomized & No clear & No clear & Low & Low & Low \\
\hline Zou [11] & Randomized & No clear & No clear & Low & Low & Low \\
\hline Colleoni [12] & Randomized & No clear & No clear & Low & Low & Low \\
\hline Anderson [4] & Randomized & No clear & Double-blind & Low & Low & Low \\
\hline Lindquist [13] & No clear & No clear & No clear & Low & Low & Low \\
\hline $\begin{array}{l}\text { Yuenyongviwat } \\
{[14]}\end{array}$ & No clear & No clear & No clear & Low & Low & Low \\
\hline Huang [15] & Randomized & No clear & No clear & Low & Low & Low \\
\hline
\end{tabular}

\section{Characteristics of the eligible studies}

In this study, the year of publication, country, number of cases, postoperative drug use, and other basic information in the included literature were extracted, and the general characteristics of the included study were shown in Table 1.

\section{Quality of the eligible studies}

A total of 7 literatures were included in this metaanalysis, among which 5 trials [4, 10-12, 15] were randomized controlled trials (RCTs) and 2 trials [13, 14] were retrospective studies. In all the five RCT studies, reasonable randomization methods and hidden allocation methods were given, and in one of them, double-blind methods were used, with a low risk of bias. The quality evaluation table of literature is shown in Table 2.

\section{Results of the meta-analysis for outcomes The incidence of VTE}

Six studies including 4333 patients compared the incidence of perioperative VTE events between the rivaroxaban and aspirin groups [4, 10-12, 14, 15]. The metaanalysis showed that there was no statistically significant difference in the incidence of postoperative VTE between the two groups ( $\mathrm{RR}=0.75,95 \%$ CI $0.50-1.11, I^{2}=$ $36 \%, p=0.15)$, as shown in Fig. 2 .

\section{Major bleeding}

Four studies with 4775 participants reported data for major bleeding [4, 13-15]. In total, 12 out of 2425 patients in the rivaroxaban group experienced major bleeding, while 11 out of 2350 patients in the aspirin group experienced major bleeding. The results showed that there were no significant differences in major bleeding between the rivaroxaban and aspirin groups $(\mathrm{RR}=0.94,95 \% \mathrm{CI} 0.45-$ $\left.2.37, I^{2}=21 \%, p=0.94\right)$, as shown in Fig. 3 .

\section{Nonmajor bleeding}

Five studies with 4832 patients reported data for the incidence of nonmajor bleeding [4,11, 13-15]. The analysis showed that rivaroxaban increased the incidence of nonmajor bleeding compared with aspirin $(\mathrm{RR}=1.29$, $95 \%$ CI $\left.1.05-1.58, I^{2}=0 \%, p=0.02\right)$, as shown in Fig. 4.

\section{All-cause mortality}

Two studies, with 3456 enrolled participants, reported the all-cause mortality in the two groups $[4,12]$. The results showed that there was no significant difference in the allcause mortality between the two groups ( $R R=0.88,95 \%$ CI $\left.0.12-6.44, I^{2}=0, p=0.90\right)$, as shown in Fig. 5 .

\section{Discussion}

We found that 7 studies evaluated the efficacy and safety of rivaroxaban versus aspirin in prevention of VTE following total joint arthroplasty or hip fracture surgery. The results demonstrated that there were no statistical

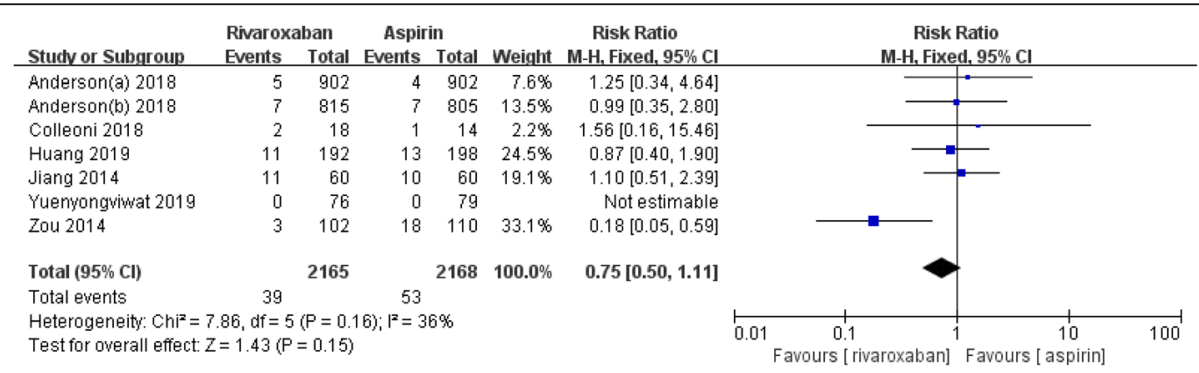

Fig. 2 Forest plot of venous thromboembolism (VTE) 


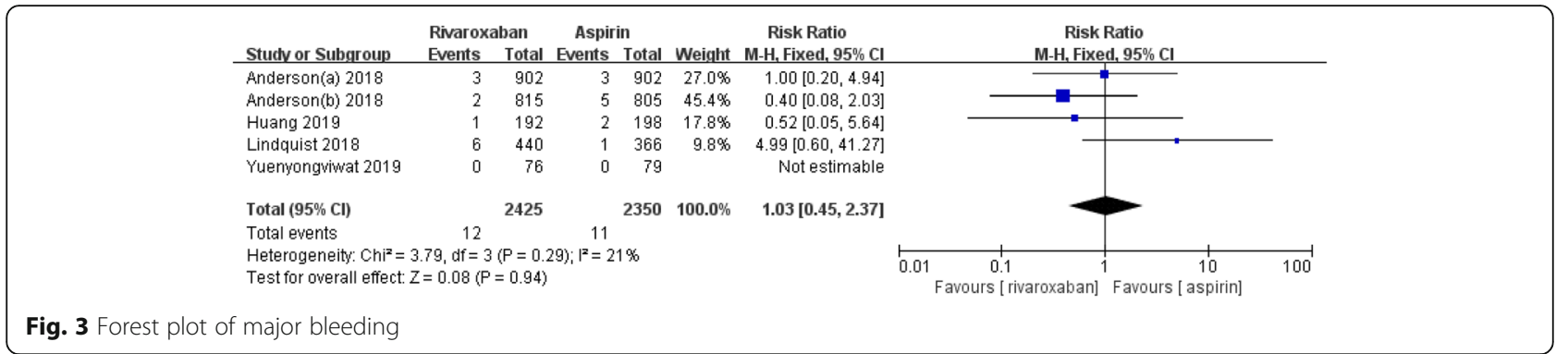

difference between rivaroxaban and aspirin in prevention of VTE and the reduction of major bleeding and allcause mortality. However, rivaroxaban had some negative side effects to patients such as nonmajor bleeding.

VTE is the most common cause of perioperative hospitalization death, and its complications consume a large amount of medical resources $[6,16]$. Anticoagulant drugs have been shown to reduce postoperative mortality and complications associated with VTE [17]. We reasoned that aspirin, because of its efficacy, low cost, and well-established side-effect profile, was potentially a good choice for thromboprophylaxis after total hip or total knee arthroplasty or hip fracture surgery [4, 18]. Rivaroxaban is the world's first oral inhibitor of factor $\mathrm{Xa}$. It is used to prevent and treat venous thromboembolism and prevent stroke or systemic embolism in atrial fibrillation [19]. It has advantages of convenient administration, rapid action, and low risk of drug interaction. In recent years, there have been more and more studies on rivaroxaban in perioperative anticoagulation, especially in prevention of VTE in patients with lower limb fractures. The use of oral anticoagulants in the perioperative period, represented by rivaroxaban, seems to be in doubt. To date, clinical trials have suggested that aspirin may be effective for prevention of venous thromboembolism postoperatively, but comparisons with direct oral anticoagulants are lacking. We pooled the patient cohort from eight studies to increase the power of these findings. In addition, we hope to provide more objective evidence for prevention of VTE.

In fact, the recent study published by Weitz et al. [19], which compares the efficacy and safety of rivaroxaban
(10 mg/day and $20 \mathrm{mg} /$ day) with aspirin in secondary prevention of VTE demonstrates the absolute superiority of the anticoagulant in reducing the incidence of thromboembolic events, without increasing bleeding. In addition, a recent meta-analysis has shown a benefit for prevention with rivaroxaban [20]. However, the inclusion criteria are not all surgical patients. Our study included patients receiving rivaroxaban and aspirin after surgery. It is well known that perioperative period is a crucial period with a high risk of VTE event but also with high risk for bleeding on the operative zone. As a matter of fact, the American Association of Orthopaedic Surgery recommends aspirin as a chemoprophylactic drug for VTE in 2012 [21]. In addition, other recent studies have shown that aspirin did not differ statistically significantly from other anticoagulants used for VTE prophylaxis after THA and TKA [22-24]. These studies support our conclusion.

In this meta-analysis, the incidence of postoperative VTE, the risk of bleeding, and all-cause mortality were compared. Compared with rivaroxaban, aspirin had no statistical difference in prevention of perioperative venous thromboembolism. Thus, our findings suggest that aspirin may be an appropriate option, which is not only cost-effective, but also has a similar ability to prevent VTE following total joint arthroplasty or hip fracture surgery.

This meta-analysis included five randomized controlled studies and two cohort studies involving a large sample of 5133 patients. These literatures were published in high-level journals, five literatures of which were published in recent 3 years, and the results were

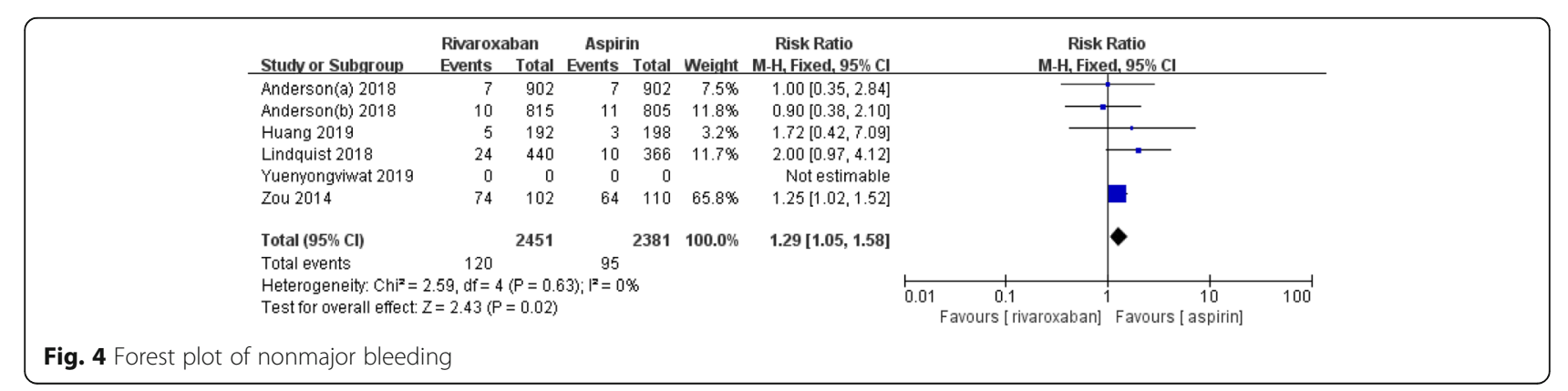




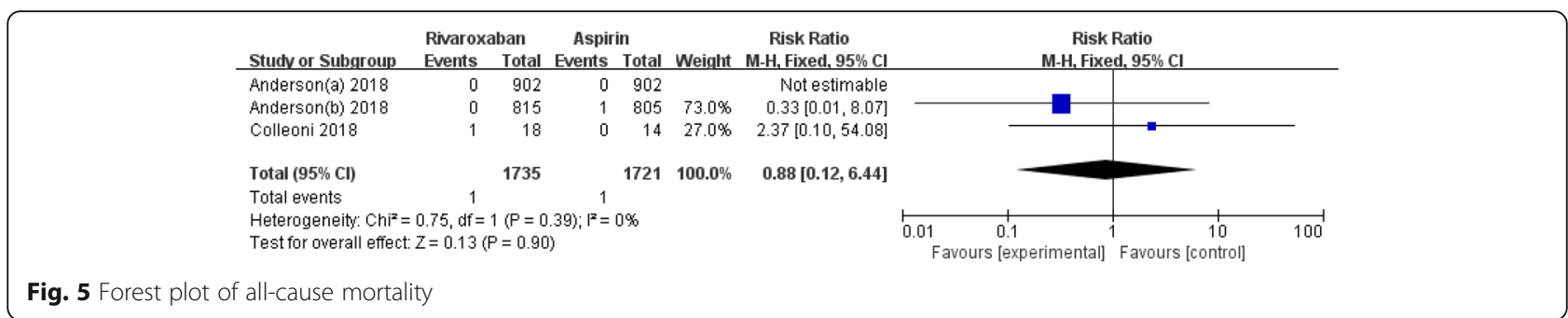

reliable. There have been numerous studies on prevention of VTE with anticoagulants, including comparisons of enoxaparin with rivaroxaban, rivaroxaban with placebo, and aspirin with placebo, with very few studies comparing rivaroxaban with aspirin. This study collected recent studies on rivaroxaban and aspirin, and comprehensively analyzed the efficacy and safety of these two drugs in prevention of perioperative VTE. With more and more people supporting cheaper aspirin, it makes sense to include all relevant studies in recent years in a metaanalysis.

This meta-analysis also has some limitations. (1) Although this study adopts a comprehensive retrieval strategy, it is still possible to miss some gray literature. (2) The sample size varied greatly among the included studies, which ranged from 32 to 3424 . Compared with larger trials, studies with small sample size were more likely to produce an overestimated treatment effect. (3) Only one study has described the use of blind methods, which may have a mixed bias. (4) When analyzing the bleeding events caused by the two drugs, we used nonmajor bleeding events instead of events other than major bleeding, and such differences may affect our final results. (5) There are also many influencing factors for the mortality of patients. Some confounding factors cannot be completely avoided in this study. (6) This study did not specifically analyze the basic diseases and medical history of the study patients. Aspirin has been shown to increase the risk of stomach bleeding. Therefore, aspirin should be used with caution in a patient with a history of stomach ulcers.

\section{Conclusion}

The results of this meta-study found aspirin no significant difference in the efficacy and safety of aspirin in prevention of VTE when compared with rivaroxaban. Aspirin may be an effective, safe, convenient, and cheap alternative for prevention of VTE following total joint arthroplasty or hip fracture surgery. Our study needs to be validated with more high-quality, large-sample RCTs.

\section{Supplementary Information}

The online version contains supplementary material available at https://doi. org/10.1186/s13018-021-02274-z.

Additional file 1:. PRISMA 2009 Checklist.

\begin{abstract}
Abbreviations
VTE: Venous thromboembolis; TKA: Total knee arthroplasty; THA: Total hip arthroplasty; Cl: Confidence interval; RR: Risk ratio; DVT: Deep vein thrombosis; PE: Pulmonary embolism; LMWH: Low molecular weight heparin; HFS: Hip fracture surgery; RCTs: Randomized controlled trials
\end{abstract}

\section{Acknowledgements \\ Not applicable.}

\section{Authors' contributions}

HBS, JLX, and THX conducted the literature search and data analysis. HBS drafted the manuscript. YJ and DZP revised the manuscript. All authors read and approved the final manuscript. HBS and JLX contributed equally to this work.

\section{Funding}

This work was funded by the Research Foundation of Technology Bureau of Anhui Province, China (grant No. 201904a07020026).

\section{Availability of data and materials}

The datasets used and analyzed during the current study are available from the corresponding author on reasonable request.

\section{Ethics approval and consent to participate}

Not applicable.

\section{Consent for publication}

Not applicable.

\section{Competing interests}

The authors declare no competing interests.

\section{Author details}

${ }^{1}$ Department of Anesthesiology, The First Affiliated Hospital of Wannan Medical College, No.2, West Road of Zheshan, Wuhu 241000, Anhui, China. ${ }^{2}$ Department of Cardiology, The First Affiliated Hospital of Wannan Medical College, Wuhu, Anhui, China.

Received: 25 December 2020 Accepted: 1 February 2021

Published online: 13 February 2021

\section{References}

1. Piovella F, Wang CJ, Lu H, Lee K, Lee LH, Lee WC, et al. Deep-vein thrombosis rates after major orthopedic surgery in Asia. An epidemiological study based on postoperative screening with centrally adjudicated bilateral venography. J Thromb Haemost. 2005;3(12):2664-70.

2. Memtsoudis SG, Pumberger M, Ma Y, Chiu YL, Fritsch G, Gerner P, et al. Epidemiology and risk factors for perioperative mortality after total hip and knee arthroplasty. J Orthop Res. 2012;30(11):1811-21.

3. Yu HT, Dylan ML, Lin J, Dubois RW. Hospitals' compliance with prophylaxis guidelines for venous thromboembolism. Am J Health-System Pharm. 2007; 64(1):69-76

4. Anderson DR, Dunbar M, Murnaghan J, Kahn SR, Gross P, Forsythe M, et al. Aspirin or rivaroxaban for VTE prophylaxis after hip or knee arthroplasty. N Engl J Med. 2018;378(8):699-707.

5. Chung I, Lip GY. Virchow's triad revisited: blood constituents. Pathophysiol Haemost Thromb. 2003;33:449-54.

6. Cohen AT, Tapson VF, Bergmann JF, Goldhaber SZ, Kakkar AK, Deslandes B, et al. Venous thromboembolism risk and prophylaxis in the acute hospital 
care setting (ENDORSE study): a multinational cross-sectional study. Lancet. 2008:371(9610):387-94.

7. Fassiadis N. Rivaroxaban: direct factor Xa inhibition to treat acute deep vein thrombosis. Br J Hosp Med (London, England: 2005). 2011;72(9):486.

8. Seagrave KG, Fletcher JP, Hitos K. Aspirin for prevention of venous thromboembolism in recipients of major lower-limb orthopedic surgery: a systematic review of level I evidence. Int Angiol. 2019;38(6):429-42.

9. Anderson DR, Dunbar MJ, Bohm ER, Belzile E, Kahn SR, Zukor D, et al. Aspirin versus low-molecular-weight heparin for extended venous thromboembolism prophylaxis after total hip arthroplasty: a randomized trial. Ann Intern Med. 2013;158(11):800-6.

10. Jiang Y, Du H, Liu J, Zhou Y. Aspirin combined with mechanical measures to prevent venous thromboembolism after total knee arthroplasty: a randomized controlled trial. Chin Med J. 2014;127(12):2201-5.

11. Zou Y, Tian S, Wang Y, Sun K. Administering aspirin, rivaroxaban and lowmolecular-weight heparin to prevent deep venous thrombosis after total knee arthroplasty. Blood Coagul Fibrinolysis. 2014;25(7):660-4.

12. Colleoni JL, Ribeiro FN, Mos P, Reis JP, Oliveira HR, Miura BK. Venous thromboembolism prophylaxis after total knee arthroplasty (TKA): aspirin vs. rivaroxaban. Rev Bras Ortop. 2018;53(1):22-7.

13. Lindquist DE, Stewart DW, Brewster A, Waldroup C, Odle BL, Burchette JE, et al. Comparison of postoperative bleeding in total hip and knee arthroplasty patients receiving rivaroxaban, enoxaparin, or aspirin for thromboprophylaxis. Clin Appl Thromb Hemost. 2018;24(8):1315-21.

14. Yuenyongviwat $\mathrm{V}$, Tuntarattanapong $\mathrm{P}$, Chuaychoosakoon $\mathrm{C}$, lemsaengchairat $\mathrm{C}$, lamthanaporn $\mathrm{K}$, Hongnaparak T. Aspirin versus rivaroxaban in postoperative bleeding after total knee arthroplasty: a retrospective case-matched study. Eur J Orthop Surg Traumatol. 2019;29(4): 877-81.

15. Huang $Q$, Xing SX, Zeng Y, Si HB, Zhou ZK, Shen B. Comparison of the efficacy and safety of aspirin and rivaroxaban following enoxaparin treatment for prevention of venous thromboembolism after hip fracture surgery. Orthop Surg. 2019;11(5):886-94.

16. Centers for Disease Control and Prevention (CDC). Venous thromboembolism in adult hospitalizations - United States, 2007-2009. MMWR. 2012;61(22):401-4.

17. Kearon C, Akl EA, Ornelas J, Blaivas A, Jimenez D, Bounameaux H, et al. Antithrombotic therapy for VTE disease: CHEST guideline and expert panel report. CHEST. 2016;149(2):315-52.

18. Prandoni P, Lensing A, Prins MH, Gebel M, Pap AF, Homering M, et al. Benefits and risks of extended treatment of venous thromboembolism with rivaroxaban or with aspirin. Thromb Res. 2018;168:121-9.

19. Weitz Jl, Lensing A, Prins MH, Bauersachs R, Beyer-Westendorf J, Bounameaux $\mathrm{H}$, et al. Rivaroxaban or aspirin for extended treatment of venous thromboembolism. N Engl J Med. 2017;376(13):1211-22.

20. Xie J, Jiang M, Lin Y, Deng H, Xie X, Li L. Rivaroxaban versus aspirin in prevention of venous thromboembolism: a meta-analysis of 9 randomized controlled trials comprising 7,656 patients. Thromb Haemost. 2019;119(9): $1517-26$.

21. Falck-Ytter Y, Francis CW, Johanson NA, Curley C, Dahl OE, Schulman S, et al. Prevention of VTE in orthopedic surgery patients: antithrombotic therapy and prevention of thrombosis, 9th ed: American College of Chest Physicians evidence-based clinical practice guidelines. Chest. 2012;141:e278S-325S.

22. Xu J, Kanagaratnam A, Cao JY, Chaggar GS, Bruce W. A comparison of aspirin against rivaroxaban for venous thromboembolism prophylaxis after hip or knee arthroplasty: a meta-analysis. J Orthop Surg (Hong Kong). 2020; 28(1):615556312

23. Ni CS, Fleming A, Dahly D, Kehoe E, O'Byrne JM, McGrath B, et al. Aspirin compared to enoxaparin or rivaroxaban for thromboprophylaxis following hip and knee replacement. Int J Clin Pharm. 2020;42(3):853-60.

24. Matharu GS, Kunutsor SK, Judge A, Blom AW, Whitehouse MR. Clinical effectiveness and safety of aspirin for venous thromboembolism prophylaxis after total hip and knee replacement: a systematic review and meta-analysis of randomized clinical trials. JAMA Intern Med. 2020;180(3):376.

\section{Publisher's Note}

Springer Nature remains neutral with regard to jurisdictional claims in published maps and institutional affiliations.

Ready to submit your research? Choose BMC and benefit from:

- fast, convenient online submission

- thorough peer review by experienced researchers in your field

- rapid publication on acceptance

- support for research data, including large and complex data types

- gold Open Access which fosters wider collaboration and increased citations

- maximum visibility for your research: over $100 \mathrm{M}$ website views per year

At BMC, research is always in progress.

Learn more biomedcentral.com/submissions 